\title{
Creating the Foundation of a Healthcare Research Project
}

\author{
Bobeica Ana Maria \\ Academy of Economic Studies, Bucharest, Romania
}

\begin{abstract}
The research topic of this paper develops a case study approach that builds on the foundations of Yin's "linear model” and "the best practice" used in theoretical case studies at international research literature. It discusses the case study method and its role and focusing on research questions like healthcare branding, research design, and methodic. Also presents the case study research theory for a research case study. The methods used in this paper are based on hypothesis of a generic hospital branding strategy for the Romanian Private Hospital and also may apply to the Romanian strategy of development of public healthcare entities and partnerships between public and private healthcare entities. An empirical test of the relationships among branding loyalty and awareness, customer satisfaction, trust and relationship commitment suggests that Romanian hospitals can be successful in creating an image and positive brand equity if they can manage their customer relationships well. This can be done through a coordinated strategy of management and marketing development of healthcare entities. The results highlight the dominance of case-study research in qualitative marketing healthcare and highlight the importance of customer relationships in the branding practice of healthcare marketing. It also shows that marketing managers can succeed in creating positive brand equity and image if they can manage relationships with their customers well.

Keywords: healthcare marketing, research case study, branding in healthcare, customer relationship, brand equity, healthcare research, case study research, quality of research, quality management
\end{abstract}

\section{Introduction}

The paper emphasizes on the best practice of a case study in the international literature, based on known research and proposes a research model in the form a case study with multiple hypotheses and a research design for the Romanian healthcare market. The importance of the research is everlasting by the fact that there is a direct and positive connection between brand equity and customer relationship management. The entire hypothesis proposed in this research is correct and represent a basis for a future analysis in a healthcare research project of Romanian healthcare industry. Yin's research theory as presented and discussed in this paper and also "the best practice in practice" for a successful case study should be taken into account in order to pursue, define, and succeed in creating a bright and intelligent research case study in the years to come where branding and the principle defined by Gil Bashe are the basis for a successful healthcare marketing research.

Bobeica Ana Maria, Ph.D. candidate, Faculty of Marketing, Academy of Economic Studies.

Correspondence concerning this article should be addressed to Bobeica Ana Maria, Sf Vineri 25, bloc 105c, ap 74, sector 3, Bucharest, Romania. E-mail: a_bobeica@yahoo.com. 


\section{The Case Study Method: Definition and Typology}

Defined most generally the case study is a description of a management situation. In the paper Case Study Research-Designs and method, Yin (2003) emphasizes on three different types of case studies: exploratory, descriptive any causal, and explanatory. Further to the classification of case studies, there are various options available to the researcher in terms of the design or structure of the case study project. The researcher can employ either a single or a multiple case designs depending on different design situations and further to this dichotomy, can also choose between an embedded and a holistic case study design, reflecting unitary or multiple units of analysis within the case or cases. Yin (2003) outcomes an additional classification of case study designs: embedded and holistic designs. This classification relates to the level of analysis within the case or cases. Thus Yin's typology of case studies results in a $2 \times 2$ matrix composed of a single case embedded design, single case holistic designs, and multiple cases embedded designs and multiple case holistic designs. If a case study is about a single organization, such as hospital (healthcare industry) and embedded design might yield outcomes which are the best method used in order to have some major results an impact the market.

\section{Short History of Case Study Research}

There is a chronology over years of the quality of the papers which referr to the case studies research phenomena. All of these rerearch have been published in different studies across the time but there is a convergence of the authors on the next one: 1971-1979: During this period of time some eight case study were published during this times. For all of these published case studies, the principal characteristic is the lack of raw data presented to usual readers. 1980-1989: Nine cases have been published during this 1980-1989. In regards to research quality, all of these cases actually provided less data than those published before, even though suggested standards were beginning to emerge when you are referring to the quality of business research. So very few researchers considered some issues of validity that we had to divert from all considerations of validity (construct and internal) into a single category called "validity". The authors of the study have chosen to focus on external validity as a different issue as more authors at international level considered this, but at the end of their articles as a future theme to study. 1990-1999: Between this period of time, 27 cases have been published during 1990-1999. As with the previous period, the debate regarding quality in case study research was intense in the economic and business disciplines and qualitative research began to be published largely also in important marketing journals. Furthermore, practical (non-theory) books on qualitative methods of research and case research were also widely available. The in depth analysis of the research cases published during this period of time showed that $59 \%$ provided had no methodological details, 52\% provided no details on secondary sources used, some $67 \%$ did not use any triangulation, $55 \%$ of the papers provided no justification for the method used, and 63\% of the case studies presented no raw data. 2000-2006: 61 research cases were published during this period of time. The analysis shows the view that authors are more likely to address the issues of quality, although much more could be done in order to allow colleagues to make real based judgments about the issues of validity, reliability, and even generalizing. In conclusion, $62 \%$ of the research justified their choice of method, 89\% case studies provided enough background case or industry details in order to make judgments on the conditions of findings, $72 \%$ of them provided sufficient detail about their methods of study, $36 \%$ of them have provided detail about the questions asked and engaged in any triangulation, $31 \%$ of case studies 
provided details about the analysis procedures, and $26 \%$ of the case studies provided raw data. Given the increase in the number of cases published during this period, the emerging issues in relation to quality were also more complex. As well as the issues covered above in previous sections (evidence that would allow any judgments of quality), practical quality concerns are presented in regards to data information from large samples of multiple case studies, the use of multiple secondary data, and the relative importance of various quality methods. As seen above there is a continuous improvement over the years in general study, concept, and research of case studies related to the marketing industry focusing lately into the concept of "quality research". Also there is an important need in the near future to make an analysis on the studies already published in the recent literature since 2006 and 2013. We hope that our findings will notice significant improvement in the case study analysis and theory of best practice which are important in all areas involved and explained here.

\section{Key Characteristics of Case Study}

After Yin, the characteristics of case studies are the following: Phenomenon is to be examined in a natural setting with data being collected by multiple means. Also one or few entities (person, group, or organization) are to be examined in order to be in connection with the complexity of the unit which is to be studied intensively. Many of the case studies analyzed are more suitable for the exploration, classification, and hypothesis development stages of the knowledge process in research case studies where the investigator should have a receptive attitude towards exploration of new routes. No experimental control or manipulations have to be involved in this phase and also the investigator may not specify the set of independent and dependent variables in advance of the research. Also the results that derived depend heavily on the integrative powers of the investigator of the research where changes in the site selection and data collection used methodology could take place as the investigator develops new hypotheses of work. The case study research is useful in the study of "why" and "how" questions because it deals with operational things that are tracked over time rather than using the frequency or incidence meanwhile the focus being on the contemporary events.

\section{Establishing Objectives of Research for a Case Study}

In the case of a "qualitative research" which is the latest "option" in the area of case study marketing research, the objectives for a future research in the area of healthcare rebranding may include: Qualitative research is concerned primarily with process, rather than outcomes or products. First objective: Looking on the process of rebranding. Qualitative research is interested in meaningful results. Second objective: Focus on the theory versus practice, the qualitative research is the primary instrument for data collection and analysis. Third objective: Collecting relevant data and analysis qualitative research involves fieldwork. Fourth objective: Interview with relevant people, discussion with key people involved in the process, or relevant marketing executives in healthcare and quality leaders. Qualitative research is descriptive in that the researcher is interested in process, meaning, and understanding gained trough words or picture. Fifth objective: Based on relevant data collection, make assumptions. The process of qualitative research is inductive in that the researcher builds abstractions, concepts, hypothesis, and theories from details. Sixth objective: Make conclusions, and add personal opinions based on relevant material. The characteristics of a case study objectives are: (1) the case study must be significant; (2) the case study must be complete; (3) the case study 
must consider alternative perspective; (4) the case study must display sufficient evidence; and (5) the case study must be composed in an engaging matter.

\section{Best Practice in Practice for a Case Study}

(1) Primarily theory building case studies. The authors provide a linkage between their research effort and theory; (2) The selection of case study phenomena is based on the rationale of purposeful sampling; (3) These case studies include different sources of data, namely, in-depth interviews, observation, and archival records; (4) The selection of interview respondents ensures that data is collected from actors with different perspectives with respect to investigated phenomena (e.g., employees, management, internal and external actors of a firm etc.); (5) The authors explain the process of data analysis; more sophisticated methods to data analysis are employed: pattern matching and constant comparison of findings with theory; (6) The coding process is often conducted using specialized software such as Nudist, N Vivo, or Decision Support Analysis software; (7) Findings are presented using: within and/or cross case study analysis, case history analysis, thematic analysis, comparison between theory and data; and (8) The authors apply some triangulation techniques (data, between method and investigator triangulation) and possibly seek respondent validation on case study findings and reports presented. All of these results are presented in future analysis and improve our view of the best practice in practice for a case study. This is important also for the development of the research method and the model presented below in the actual case study of this paper.

\section{Healthcare Branding and the 10 Most Important Principles of Branding}

Characteristics of a good healthcare brand can be summed up in the "10 Principle of Branding" at outlined in the Bashe and Hicks's (2010) book Branding Health Services: (1) Deliver on functionality; (2) Have a right window of safety; (3) Be right on price; (4) Speak with "one tongue"; (5) Be operationally effective versus merely operationally efficient; (6) Be "Glocal” (see second principle above); (7) Be an "outside in” brand; (8) Be loyal; (9) Franchise, franchise, franchise etc.; and (10) Ace out in the "affinity” department areas.

\section{Theory and Hypothesis for the Research}

Healthcare managers and marketers face unique challenges today, due in part to the role the health care in contributing to public welfare and global crisis. Hospital marketing in Romanian latest history is particularly challenging since there are not many private institutes, most of the system being public, and the public not making any type of advertising in order to attract customers. As a result, Romanian hospitals depend heavily on customer relationship management (CRM). This study identifies some key factors that influence the creation of brand equity with the help of customer relationships: trust, customer satisfaction, relationship commitment, brand loyalty, and brand awareness. An empirical test of the relationships among these factors suggests that hospitals can be successful in the creation of image and positive brand equity if they can manage their customer relationships well. Proposed hypotheses: H1: Trust influences brand loyalty positively (+); H2: Trust influences brand awareness $(+)$; H3: Customer satisfaction influences brand loyalty $(+)$; H4: Customer satisfaction influences brand awareness (+); H5: Relationship commitment influences brand loyalty $(+)$; H6: Relationship commitment influences brand awareness $(+)$; H7: Brand loyalty influences brand equity $(+)$; H8: Brand 
awareness influences brand equity (+); H9: Brand equity influences hospital image (+); H10: Trust influences hospital image (+); H11: Customer satisfaction influences hospital image $(+)$; and H12: Relationship commitment influences hospital image $(+)$. This can be also seen in Figure 1 (see Research Model).

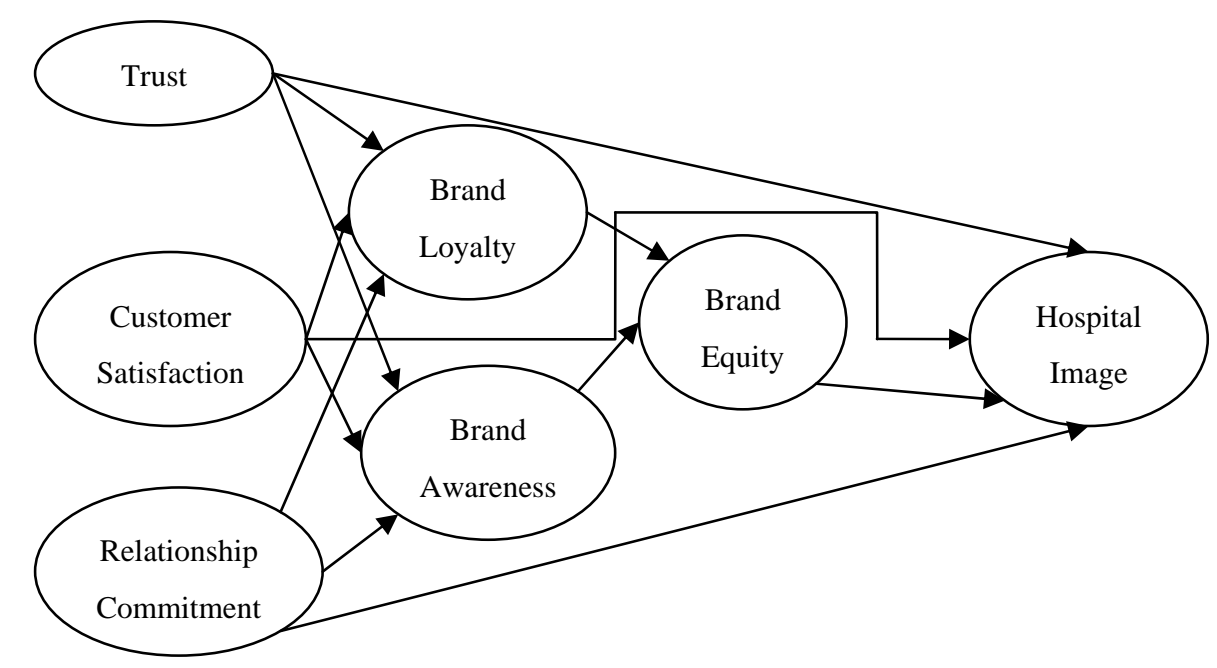

Figure 1. Research model: Structural path diagram of theory and hypothesis.

\section{Research Design, Method, and Model of Research}

All these Hypotheses in this study are correct. At a first view, Romanian hospitals should focus their marketing efforts on customers that trust the healthcare entity or the doctors that practice in the hospital. They should invest resources to create and maintain this high level of trust for their medical service with the hope that it will lead to positive brand equity and hospital image. So hospitals should create and maintain strong customer relationships in order to increase customers' commitment. They must remember the importance of creating brand awareness in order to create positive brand equity and hence cultivate hospital image. Finally, hospital managers must learn how to connect their brand loyalty to brand equity. Government official must implement effective communicational plans in the public sector and marketing managers in the private healthcare institutions through advertising and customer relationship management (CRM). This study shows that managers can succeed in creating positive brand equity and image if they can manage relationships with their customers well. Also shows the direct connection between these two important characteristics of the model as very important key factors between: trust, customer satisfaction, brand loyalty, and awareness.

\section{Important Conclusions and Recommendations}

Our intent in this paper was to clarify the nature of the case research method, explain why it might be utilized in marketing research studies and offer some suggestions for future construction and improvement of the research paper on healthcare marketing quality and rebranding. We would argue that our review has given insight into what case researchers in this field mean by "case study" and the best practices they associate with this methodology. The main finding here was that Yin's literature was a strong influence, not just on the methodological literature in industrial marketing, but on research practice as well. This can be found in the 
pattern of citations, with Yin by far the most popular source, as well as the widespread use of some of his key recommendations, particularly purposeful sampling, triangulation, and systematic data analysis. The managerial implications emphasize the importance of continuing to meet core brand values yet becoming relevant to contemporary needs. The findings underscore a company's need to fully understand and preserve its core values and also undertaken some major steps in order to fulfill its destiny and succeed in the future markets.

\section{References}

Bashe, G., \& Hicks, N. (2000). Branding health services. Gaithersburg, M.D.: Aspen Publishers.

Benbasat, I., Goldstein, D. K., \& Mead, M. (1987). The case research strategy in studies of information systems. MIS Quarterly, 11(3), 369-386.

Beverland, M., \& Lindgreen, A. (2010). What makes a good case study? A positivist review of qualitative case research, industrial marketing management, 1971-2006. Industrial Marketing Management, 39(1), 56-63.

Diamond, P. (1992). Organizing the health insurance market. Econometrica, 60(6), 1233-1254.

Dubois, A., \& Gibbert, M. (2010). From complexity to transparency: Managing the interplay between theory, method and empirical phenomena in IMM case studies. Industrial Marketing Management, 39, 129-136.

Fox-Wolfgramm, S. J. (1997). Towards developing a methodology for doing: Qualitative research: The dynamic-comparative case study method. Scandinavian Journal of Management, 13(4), 439-455.

Hindle, T., Checkland, P., Mumford, M., \& Worthington, D. (1995). Developing a methodology for multidisciplinary action research: A case study. Journal of the Operational Research Society, 46(4), 453-464.

Järvensivu, T., \& Törnroos, J. A. (2010). Case study research with moderate constructionism: Conceptualization and practical illustration. Industrial Marketing Management, 39, 100-108.

Lee, A. S. (1989). A scientific methodology for MIS case studies. MIS Quarterly, 13(1), 33-50.

Piekkari, R., Plakoyiannaki, E., \& Welch, C. (2010). Good case research in industrial marketing: Insights from research practice. Industrial Marketing Management, 39, 109-117.

Size, M. (2005). Rebranding: A case study approach. Dublin: Dublin Institute of Technology.

Stuart, I., McCutcheon, D., Handfield, R., McLachlin, R., \& Samson, D. (2002). Effective case research in operations management: A process perspective. Journal of Operations Management, 20, 419-433.

Yin, R. K. (2003). Case study research—Designs and method. Thousand Oaks, C.A.: Sage Publications. 